\title{
ОЦЕНКА СОЦИАЛЬНОГО САМОЧУВСТВИЯ И ДЕЯТЕЛЬНОСТИ ПОЛИТИЧЕСКИХ ЛИДЕРОВ В УСЛОВИЯХ ПАНДЕМИИ COVID-19 (В ЗЕРКАЛЕ ФОКУС-ГРУПП)
}

\section{А.В. Шентякова}

anna_pedagog@mail.ru Санкт-Петербургский государственный университет Санкт-Петербург, Россия

Цитирование: Шентякова А.В. Оценка социального самочувствия и деятельности политических лидеров в условиях пандемии COVID-19 (в зеркале фокусгрупп) // Власть и элиты. 2021. Т. 8, № 2. С. 55-71.

DOI: https://doi.org/10.31119/pe.2021.8.2.3

Аннотация. Рассматриваются результаты прикладного исследования об особенностях восприятия жителями регионов деятельности политических лидеров в условиях пандемии коронавируса. Целью исследования было выявление динамики в отночении к политическим лидерам со стороны представителей разных соииальных групп в кризисных условиях. Исследование восприятия гражданами рисков, проблем, своего самочувствия и влияние этих факторов на отношение к властным структурам и политическим лидерам проводилось с использованием метода фокусгрупп. Групповые дискуссии позволили выявить ряд изменений в сознании и оценках жителей регионов. В кризисных условиях существенно вырос запрос на две составляющих эббективной работы государственных органов: с одной стороны, на оперативность реагирования, с другой - на обратную связь и информационное сопровождение принимаемых решений. Оба параметра оценки значительно связаны с уровнем тегитимности власти. При оценке ситуации пандемии и решений всего спектра проблем со стороны органов власти важным фактором стал тип населенного пункта и возраст участников. Гендерный фактор показал слабое влияние. 
Среди молодьх участников бокус-групп усилились оппозиционные настроения и негативное отношение к властным институтам и отдельным лидерам. Люди среднего возраста (35-50 лет) отмечали рост негативных оценок работы системы властных структур, отсутствие реальных лидерских качеств среди региональных политиков. Анализ данных показал снижение уровня доверия к президенту и изменение в восприятии его образа среди самой старшей возрастной группь.

Ключевые слова: пандемия COVID-19, социальное самочувствие, политические лидерь, легитимность, фокус-группа.

Фактор пандемии COVID-19 негативно повлиял на социальное и экономическое самочувствие граждан, на структуру и занятость в сфере экономики и социальной сферы, что отразилось на характере политического и электорального процессов в период избирательной кампании. Негативные последствия для экономики и социальной жизни проявились и в обострении социального неравенства, и в нарушении социальных взаимодействий, и в повышении уровня социально-политической тревожности [Великая, Белова 2021: 86].

В условиях возросших рисков и социальной напряженности произошли изменения во взглядах, оценках и представлениях людей о политических институтах, лидерах. Публичная дискуссия и сетевой дискурс, возникшие в отношении усилий власти по преодолению последствий пандемии, приобрели политический характер в контексте формирования электоральных предпочтений граждан при голосовании за партии на выборах в Госдуму восьмого созыва [Левашов, Великая 2021: 3]. В кризисных условиях существенно вырос запрос на две составляющих эффективной работы государственных органов: с одной стороны, на оперативность реагирования, с другой - на обратную связь и информационное сопровождение принимаемых решений. Оба параметра оценки в значительной степени связаны с уровнем легитимности власти. Легитимность основывается на принципах и механизмах доверия общества к политическим институтам и лидерам. Выстраивание диалога, создание площадок для обсуждения спорных моментов в процессе борьбы с эпидемией оказались нужны не только наиболее образованной и активной части граждан, но и тем, кто раньше не интересовался политическими решениями и нормативными документами. С одной стороны, в обществе был сформирован запрос к власти на принятие и обеспечение своевременных и эффективных мер для предотвращения/распространения инфекции и минимизации ее послед- 
ствий. С другой стороны, кризис легитимности, не только по отношению к власти, проявился наиболее ярко на фоне дискуссии и жестких споров по вопросу вакцинации. Пандемия выступила как катализатор и обострила проблемы, которые существовали, но в сознании многих людей не были серьезно актуализированы. Низкий уровень доверия к таким институтам, как СМИ или региональные органы власти, который раньше фиксировали многочисленные опросы общественного мнения, в кризисной ситуации привел к тотальному недоверию почти ко всем мерам борьбы с вирусом, которые предпринимались властями. В ситуации различных ограничительных мер основным полем для дискуссий стал интернет, но на этой площадке официальный дискурс власти представлен фрагментарно и слабо.

Выявление социального самочувствия граждан, оценка политической и социально-экономической ситуации в кризисные периоды представляется особенно важным. Эти показатели позволяют оценить социальную эффективность антикризисных мер, которые принимаются со стороны государства. Исследование восприятия гражданами рисков, проблем, своего самочувствия и влияние этих факторов на отношение к властным структурам и политическим лидерам по прошествии года с начала эпидемии позволило выявить ряд изменений в сознании и оценках жителей регионов. Исследование носило инициативный характер и финансировалось частными лицами. В статье используется только часть эмпирических материалов.

Для изучения социальных и политических компонентов и их связи с электоральными ожиданиями применены качественные методы сбора и анализа данных. Фокусированное групповое интервью как метод позволяет собрать информацию непосредственно у респондентов, не ограничивая их рамками стандартизованных анкет или опросников. Фокусгруппа направлена на определение отношения участников к поставленной проблеме, выявление причин и мотивации восприятия того или иного объекта, что позволяет использовать в качестве концептуальной основы интерпретационный подход. По шесть фокус-групп было проведено в каждом из трех субъектов России: Санкт-Петербурге, Ленинградской и Вологодской областях. В Ленинградской области фокусгруппы проходили в трех районах, которые были выбраны по критериям максимального различия: Кингисеппском, Лодейнопольском и Лужском. В Вологодской области для исследования также были отобраны три района - Устюженский, Бабаевский и Шекснинский. Из 
шести групп в Вологодской и Ленинградской областях три фокус-группы проводились с участием жителей крупных городов (Череповец, Великий Устюг, Бабаево, Кингисепп, Луга) и еще три групповых дискуссии состояли из жителей сельской местности (п. Шексна, с. Чёбскарское, п. Заклинье, п. Котельский, пгт. Лодейное поле). В каждой фокусгруппе было по десять человек. Всего участвовало 180 респондентов. Эмпирическая часть исследования была проведена в мае-июне 2021 г.

Группы формировались по возрастному критерию гомогенности. Были выделены три возрастные когорты: молодые участники в возрасте до 35 лет, вторая возрастная группа собиралась из людей в возрасте от 35 до 50 лет, старшая возрастная группа включала участников старше 55 лет. По гендерному представительству группы были смешанные, по десять участников в пропорции 50/50 мужчин и женщин. По уровню образования состав тоже был смешанный, но пропорционально были представлены три группы: люди с высшим образованием, со средним специальным и средним профессиональным, только со средним полным образованием. Этап сбора информации проходил в мае-июне 2021 г. Анализ данных осуществлялся в конце июня - начале июля 2021 г. и основные акценты выводов направлены не только на социальнополитическое, социально-психологическое состояние граждан, но и на оценки предвыборных ожиданий и настроений.

В сценарии были три блока вопросов. Первый блок связан с социальными проблемами, рисками, опасениями. Второй блок посвящен оценкам ситуации, которая сложилась в регионе/населенных пунктах. В этот блок вошли вопросы по оценке работы органов власти и отдельных политических лидеров всех уровней. Третий блок состоял из вопросов о грядущих выборах депутатов в Государственную Думу, об ожиданиях, оценках и отношении к партиям и кандидатам. Анализ фокус-групп продемонстрировал изменения в восприятии как политических лидеров, так и органов власти в целом представителями разных возрастных когорт.

\section{СОЦИАЛЬНОЕ САМОЧУВСТВИЕ, РИСКИ И ОПАСЕНИЯ ГРАЖДАН}

Ответы на вопросы, связанные с указанием определенных рисков и опасений, которые беспокоят и волнуют наших респондентов в большей степени, можно условно разделить на две группы. Первая группа - 
экономические риски. Они назывались очень часто и попали в тройку лидеров. Страх потерять работу, был назван во всех трех регионах без корреляционной связи с возрастом, полом, образованием или местом жительства. Понимание, что уровень реальных доходов падает, а цены на товары и услуги растут, создает базис для постоянно стресса и недовольства. Чуть в меньшей степени эти опасения проявились у лиц старшей возрастной группы, которые утверждали: Хуже, чем в 1990-е уже не будет, а значит мы переживем (ж., 67 лет, Ленинградская обл.); Пока есть мой участок и скотина, с голоду не умрем (м., 69 лет, Вологодская обл.); Было тяжелее после развала Союза, но мы выжили и сейчас как-нибудь переживем (ж., 71 год, Санкт-Петербург). Самые серьезные опасения в этой группе рисков ожидаемо высказали участники в возрасте 35-50 лет, для которых потеря работы и постоянного, определенного уровня дохода - очень серьезный фактор риска: Если я потеряю работу или еще снизят зарплату, нам нечем будет выплачивать ипотеку. Мы окажемся на улице, и никто нам не поможет (м., 35 лет, Санкт-Петербург); Я уже потеряла предыдущее место работы и до сих пор не работаю постоянно. Живем только на деньги мужа (ж., 37 лет, Лен. обл.); Денег, которые отложили на школьные расходы для детей, не хватило. Пришлось брать у родителей, иначе никак, хоть иди и занимай в банке (ж., 42 года, Вологодская обл.).

Значимость угроз, связанных с экономическим благосостоянием, в большей степени проявляется и артикулируется у жителей СанктПетербурга и других крупных городов. Эта группа рисков сохраняет приоритетное место, что сочетается с результатами всероссийский количественных опросов 2020 г.: «Из всего перечня возможных событий и явлений, связанных с пандемией коронавируса и относящихся к экономическим, жителей всех стран больше всего тревожит высокая инфляция (52 \%), потеря работы (51 \%) и потеря сбережений (50\%). Отметим, что у россиян более выражено проявились экономические страхи, связанные с сокращением заработной платы и потерей работы (по $58 \%$ ), однако лидерами являются страх «высокой инфляции, роста цен $(65 \%)$ и потери сбережений, накоплений (61 \%)» [Великая, Белова 2021: 85]. Необходимо отметить, что многие негативные экономические последствия пандемии люди из Вологодской и Ленинградской областей чаще связывают с общемировыми трендами, а не с действиями властей. Люди из этих регионов настроены более лояльно, чем жители мегаполиса. Это отличает петербуржцев, которые более критически оценива- 
ют возможности федеральной и региональной власти в решении отдельных экономических проблем. Возможно, это связано с тем, что многие в мегаполисе уже потеряли работу, часть своих доходов или их близкие и знакомые финансово пострадали от ограничительных мер.

Вторая группа рисков - свое здоровье и здоровье близких, что ожидаемо и логично. Этот блок опасений тесно связан с оценкой и характеристикой работы системы здравоохранения. Старшая возрастная группа во всех трех регионах выразила наибольшие опасения именно по этим показателям. Многие озвучивали страх заболеть и умереть, но про него говорят меньше, чем про страх заболеть не коронавирусом, а чем-то другим и оказаться без медицинской помощи: У нас женщина, соседка, моложе меня, умерла от аппендицита. Скорая приехала очень поздно, только через 5,5 часов после вызова. До больницы довезли, но и только (ж., 73 года, Лен. обл.); Я похоронил отияа, который умер от сердечного приступа, так как не было врача. Нашу больнииу в поселке закрыли еще 8 лет назад и других пунктов медицинской помощи нет. Даже при том, что идет борьба с эпидемией нам не выделили никого из специалистов и не открыли даже фельдшерского пункта (м., 41 год, Лен. обл.); Моя сестра рожала в роддоме и там заболела коронавирусом. Ребенка забрали и редко приносили, их перевезли в какуюто другую, специальную больницу. За ребенком почти не ухаживали, со стороны медперсонала отношение было ужасным (ж., 27 лет, Вологодская обл.). Представители средней возрастной группы несильно волнуются за себя, в большей степени - за своих родителей и близких. Для них риски здоровья актуальны в связке с экономическими потерями. Траты на лекарства и будущую реабилитацию, невозможность работать долгое время из-за тяжелого протекания болезни и риск потери работы, если ты не можешь работать более двух недель - вот основные страхи этой когортной группы.

Молодая часть респондентов призналась, что для них эти страхи не очень актуальны. Они уверены, что смогут найти работу, продолжить обучение в вузе в дистанционном формате или смогут устроиться както иначе. Заболеть они также не боятся. Есть опасения в вопросе здоровья родителей, но и они воспринимаются как что-то не угрожающее их благополучию. Также слабо выражены эти опасения у жителей сельской местности. Жители поселков отмечали, что давно уже живут без хорошей медицинской помощи, а шансов заболеть у них немного из-за малочисленности постоянных жителей и плохих дорог. 
Обсуждая различные ситуации, с которыми люди столкнулись за последний год, респонденты высказывали много негативных оценок работы как отдельных медработников и системы здравоохранения в целом, так и работы органов власти, которые сокращали количество больниц, ставок медицинских работников и денег, которые выделялись на российскую медицину. В этом блоке появляется серьезный критический лейтмотив. Он затрагивает два аспекта. С одной стороны, критика направлена на низкое качество работы системы здравоохранения, а это бюджетная сфера и зона ответственности в первую очередь федеральной власти, которая не справляется с медицинским обеспечением борьбы с эпидемией. Здесь более четко звучали критические высказывания в адрес Путина, который, по мнению участников, имел все необходимы ресурсы, чтобы выстроить более сбалансированную систему правил и мер, но не использовал свой властный потенциал: Он глава сильного государства, но не объявил ЧС, не привлек армию, не проконтролировал, как тратятся деньги, которые вылелень на медицину (м., 53 г., Вологодская обл.); Нельзя было все передавать губернаторам, у них нет таких возможностей, да и люди им не верят (ж., 52 года, Лен. обл.); Для такой свободь решений, которую он дал нашему губернатору, это должен бьть кто-то другой, но не Беглов, которьй не умеет принимать решения и нести за них ответственность. Он же ничего не может решить сам (м., 37 лет, Санкт-Петербург); У нас самая высокая смертность по стране, а ему это неважно. В Москве Собянин справляется лучше. К нам прислали губернатора, которыцй провалил все (ж., 24 года, Санкт-Петербург).

С другой стороны, критика направлена на информационное сопровождение всех противоэпидемиологических мер: Непонятно, что делать, если сам заболел. Как получать необходимье лекарства, продукть u помощь, если тебе плохо (м., 38 лет, Вологодская обл.); Нигде нет документов, в которых было бы написано, какую помощь оказывают в больницах бесплатно, а на что нужны свои деньги. Чем могут помочь родственники и близкие тех, кто госпитализирован, чтобы они там нормально себя чувствовали (м., 50 лет, Санкт-Петербург); Люди работали сутками, с риском для жизни, без необходимьх лекарств и аппаратов. А им даже не заплатили нормально, пусть бь сами депутать или чиновники из министерства поработали за такие деньги в этих условиях (ж., 45 лет, Лен. обл.).

Очевидно, что нестандартная кризисная ситуация вызывала целую серию стрессов, которые повлияли и на социально-психологическое 
самочувствие жителей мегаполисов и крупных городов, и на процесс поиска решений по преодолению сложившихся трудностей. В целом жители сельской местности более спокойно и рационально оценивают меры борьбы и действия властей. Петербуржцы и жители других крупных городов настроены более резко и критично, склонны чаще сравнивать решения наших органов власти и зарубежных лидеров. Именно для них информационной компонент в период пандемии был более востребован.

\section{ОЦЕНКА ДЕЯТЕЛЬНОСТИ ОРГАНОВ ВЛАСТИ И ПОЛИТИЧЕСКИХ ЛИДЕРОВ В ПАНДЕМИЙНЫЙ ПЕРИОД}

Этот блок ответов на вопросы состоял из двух частей. Первый компонент посвящен оценкам и отношению к президенту В.В. Путину и федеральной власти. Второй блок оценивал деятельность губернаторов и муниципальных депутатов в период активной борьбы с коронавирусной инфекцией. Обработка текстов дискуссий позволила условно всех участников разделить на несколько групп.

Первая группа - группа поддержки действующей власти, которая лояльно настроена к президенту Путину и поддерживает решения властей. В основном она состоит из пожилых людей, лояльно настроенных к власти. Для них власть в лице президента олицетворяет мощь страны. Они ассоциируют современную Россию с великой страной, у которой свой путь и своя миссия, которую все в мире уважают из-за военной мощи. Путин для них ассоциируется с восстановлением статуса России как мировой державы, который смог преодолеть нищету после распада СССР. Ельцин для них лидер, который продал страну американцам, а о Россию «вытирали ноги». Эти люди представляют активную часть электората и постоянно участвуют в выборах: Путин принял страну полностью разваленной. Восстановил армию. Вернул многие долги западным кредиторам (м., 75 лет, Вологодская обл.); Там нет никого более достойного, другие ничуть не лучше (м., 59 лет, Лен. обл.); Он добился чтобы другие страны с нами считались, а не смеялись, как это было при Ельцине. Только за это я уважаю Путина. Он умеет представлять страну на международном уровне (м., 62, Санкт-Петербург); Никогда не было такого, чтобы кто-то хотел с нами дружить просто так! Все хотят захватить себе кусок нашей территории и богатств. Путин заставил всех считаться с нами (ж., 59 лет, Санкт-Петербург). 
Пожилые люди, лояльно относящиеся к власти, дополняются консервативными, патриотично настроенными молодыми людьми: Hem никакого смысла критиковать, нужно решать и делать. Путин правильно все говорит. Нельзя допустить, чтобы у нас было как на Украине (м., 19 лет, Вологодская обл.); Пусть не все сделано хорошо, но в Европе тоже не справились с этой эпидемией, но там не говорят, ито нужно менять президентов или канилеров. Наши люди тоже в чем-то сами виновать, что все так складыьвается (ж., 21 год, Санкт-Петербург).

Вторая группа - группа разочаровавшихся, которые раньше считали себя сторонниками Путина и выступали за стабильность и порядок. Эта группа тоже в основном состоит из людей старшей возрастной когорты, но не старше 65 лет. Они ощущают улучшения качества жизни (по сравнению с периодом 1990-х годов) и боятся любых перемен, которые могут ухудшить их положение или привести к непонятным результатам. Они стабильно голосовали на выборах за партию «Единая Россия» и за Владимирова Путина на президентских выборах. Сюда входят как люди из сельской местности, чей уровень доходов небольшой, так и более обеспеченные люди (работающие в бюджетных организациях или охранных структурах в городах): Я не хочу повторения 90-х годов. Мы жили впроголодь. Криминал был страшный (ж., 52 года, Санкт-Петербург); Работы не было никакой. Денег не было (м., 61 год, Вологодская обл.); Я этого не хочу, как на Украине или Белоруссии. Пусть остается все, как есть. Со временем, все изменится. Но развитие должно быть постепенным, когда все будут готовы, а не революиионным (ж., 55 лет, Лен. обл.).

В эту группу были включены люди, для которых пандемия выступила индикатором, показавшим слабую организованность власти и низкий мобилизационный потенциал всей системы управления, не лидерское поведение Путина. Риски и страхи в условиях пандемии для пожилых участников исследования оказались очень остро воспринимаемыми. Основными слабыми местами называли неспособность организовать контроль за ситуацией через органы соцзащиты с помощью районных и муниципальных властных структур.

По мнению участников этой группы, образ сильной федеральной власти и президента В.В. Путина лично, значительно изменился в худшую сторону. Основными разочаровавшими выступили мужчины: $\mathrm{OH}$ не стал главным лидером, который отвечает за всех людей этой страны. Не использовал военных, не смог угадать и предвидеть главную 
опасность этой эпидемии. Для главнокомандующего это важно (м., 52 года, Санкт-Петербург). Женская часть респондентов была более мягкой, но образ «способного принимать решения, знающего что нужно делать» сместился в более нейтральную сторону. Превалировали такие оценки: А что в этой ситуации он может сделать? (ж., 52 года, Санкт-Петербург); В других странах лидеры государств тоже не смогли ничего сделать (ж., 57 лет, Вологодская обл.); Никто не был готов $\kappa$ этому и не мог быть готов (ж., 67 лет, Лен. обл.); Как он мог допустить такие иифры смертности? Почему никто за это не ответил? (м., 61 год, Ленобл.).

Ожидание более решительных действий, более жестких решений и представление, что Путин будет сам ездить по стране и контролировать своих чиновников, не оправдались. Стремление иметь сильного, уверенного лидера свойственно людям с такими взглядами. На сегодняшний день представители этого сегмента такого лидера уже не видят: Путин опозорился. Недостойно повел себя в трудное время для всей страны. Спрятался в бункере (м., 52 года, Санкт-Петербург). Это повлекло за собой колебания в уверенности, что Путин должен занимать кресло президента и сомнения, за какую партию голосовать на выборах депутатов в Государственную Думу. Раньше они Путина уважали и хвалили за то, что он сделал, за то, что смог использовать время высоких цен на нефть для укрепления позиций страны, а сейчас его упрекают и обвиняют в том, за что он действительно отвечает, но и за то, в чем он не виноват.

Снижение персонального рейтинга отмечают и другие отечественные социологи: «По данным на июль 2021 года, наибольшее доверие у россиян вызывают армия (66 \%), Президент РФ (50 \%) и Совет безопасности (46\%). Вместе с тем за последние 10 лет рейтинг доверия к президенту понижается, за последний год он упал на 11 пунктов. На фоне снижения рейтинга президента наблюдается и падение симпатий к правительству, что во многом может быть следствием недовольства политикой исполнительной власти во время пандемии» [Левашов, Великая 2021: 7]. Пандемия коронавируса не создала тренд, но в значительной мере усилила его. С рациональной позиции многие претензии, предъявляемые к власти, можно назвать спорными, но с эмоциональной точки зрения они звучат убедительно. Несоразмерный и противоречивый набор мер борьбы с коронавирусом со стороны федеральной власти показал, как считают наши участники, неспособность власти при- 
нимать своевременно решения и следить за их исполнением. В период подготовки к выборам в Государственную Думу это значительно ослабило позиции «Единой России».

Третья группа - индифферентные. Это самая многочисленная группа, для которой нехарактерны какие-то определенный политические взгляды, ценности, убеждения, и поэтому они ситуационно колеблются от выборов к выборам в широком диапазоне политического спектра. Входящие в состав этой группы люди мало интересуются политикой, плохо знают фамилии политических фигур, не следят за политическими новостями. Однако под действием эпидемии их отношение к сфере политики также изменилось: Путин не взял ответственность на себя, а перевел все стрелки на губернаторов (ж., 48 лет, Санкт-Петербург); Как можно было не просчитать экономические последствия слепого повторения мер, которье принимались в западньх странах? У нас нет таких денег и их никогда не дадут простьм людям (м., 52 года, Лен. обл.). У индифферентных на первый план выходят социальные требования к властям: Нужно в таких ситуациях, чтобь благополучие, здоровье и безопасность граждан страны стала приоритетом. Это государство должно быть для людей, а не наоборот (м., 48 лет, Вологодская обл.); Нужно прекратить помогать всем подряд без отдачи. Сколько можно заниматься внешней политикой, пора уже заняться и внутренними проблемами (м., 28 лет, Санкт-Петербург); Сейчас, как никогда, мь поняли, что к нам относятся как к быдлу, о каком доверии можно говорить? Никому из них нет дела как должнь жить люди с таким ростом иен и качеством медичинь (ж., 48 лет, Лен. обл.).

Именно в этой группе был актуален вопрос о достоверности информации и отсутствии понятной информации со стороны власти.

Четвертая группа - критики и оппозиционно настроенные индивиды. Это группа людей с разной степенью оппозиционных настроений. Они говорят о назревших изменениях в политической системе и считают, что никакое развитие невозможно, пока существует «вертикаль власти» и все ресурсы концентрируются в руках бюрократов. Для них важны демократические ценности, гражданские права и свободы. Они придерживаются мнения, что только сами граждане, гражданское общество, а не кто-то на уровне федеральной власти могут изменить жизнь в лучшую сторону. В большинстве своем это либо молодые люди из крупных городов, либо респонденты среднего возраста, но также 
встречаются люди старшей возрастной когорты. Главный повод для недоверия к Путину, который озвучивался многократно, - это принятые поправки в Конституцию, которые обнулили сроки его президентства. Смещение его внутриполитического курса в сторону авторитарности, вмешательство в частную жизнь людей, аресты и сроки за участие в митингах, несменяемость власти формируют оппозиционные настроения и влияют на желание предпринимать конкретные действия. Среди участников фокус-групп мало представлен сегмент радикальных оппозиционеров, которые готовы пойти на митинги и требуют свержения власти Путина. Большинство из четвертой группы не готово к активному политическому протесту или к иным формам протестного политического поведения.

Необходимо сократить количество административных работников в органах власти, сотрудников силовых ведомств. Не нужно указывать нам, что можно репостить на своей странице (м., 20 лет, СанктПетербург); Люди сами несут ответственность за себя и если не согласны с чем-то, то должны иметь возможность об этом заявить открымто (ж., 30 лет, Лен. обл.). Сколько можно сидеть и ничего не делать? Загробили частный бизнес, здравоохранение и образование развалили, только налоги собирают (м., 37 лет, Санкт-Петербург); Нам не нужен старый лидер, во власти может быть любой человек, которьй будет честно выполнять свою работу и предложит стране план развития. Желательно не старше 60 лет, и не больше 2 сроков по 4 года (ж., 27 лет, Санкт-Петербург).

Идеологический и ценностей спектр их взглядов охватывает как сторонников социализма, так и представителей либерально-демократических убеждений. Их объединяют ценности гражданского общества и протестные настроения.

Наиболее активные оппозиционеры готовы лично участвовать в протестах, но их число совсем незначительное: Пойду протестовать и очень хочу, чтобы другие люди увидели нас и поняли, как это важно (ж., 60 лет, Санкт-Петербург); Если все станет ещзе хуже, я готов выцти на акиии протеста. Хотя и не уверен, что это даст положительныци результат (м., 29 лет, СПб).

Для этой группы пандемия стала триггерной точкой, благодаря которой проявилась дисфункциональность всей системы управления. Их антипатия к президенту, партии «Единая Россия» увеличилась, но она была и до эпидемии. 


\section{ОТНОШЕНИЕ К ГУБЕРНАТОРАМ}

Позиция дистанцирования, которую выбрали президент и федеральное правительство, наделение региональных политиков особыми полномочиями продемонстрировали, по мнению всех участников групп, нежелание нести ответственность за ситуацию в каждом отдельном регионе. Большинство респондентов выразили мнение о неготовности региональных властей принимать все решения на свой страх и риск.

Жители Вологодской области наиболее лояльно оценили усилия главы региона в период пандемии. Почти все участники согласились, что губернатор справился с неожиданной ответственностью примерно на $60 \%$ В процессе выделения положительных моментов в работе О.А. Кувшинникова возрастные группы разделились. Представители старшей возрастной группы отмечали как положительный момент жесткий контроль на въездах и выездах во все крупные населенный пункты, которые расположены близко к федеральной трассе. Они оценили это как положительное решение, так как оно позволило снизить темпы заболеваемости в регионе, что могло стать серьезной проблемой в условиях крайней нехватки больничных мест и специального оборудования. Молодые участники фокус-групп указали на появление специального канала связи с губернатором через интернет. Была организована специальная горячая линия, по которой можно было обратиться с вопросом и оперативно получить ответ. Средняя возрастная группа не смогла отметить положительные стороны работы О.А. Кувшинникова, но и критических замечаний не высказала, оценив его работу нейтрально: Мы ничего от него и не ждали, чтобы расстраиваться. Где он возьмет столько врачей, больнии, или ИВЛ? Нет этого в области в таких количествах (ж., 46 лет, Вологодская. обл.).

В Ленинградской области жители оценили деятельность губернатора А.Ю. Дрозденко по борьбе с коронавирусом скорее положительно. Около половины респондентов хвалили главу региона, особенно в сравнении с Санкт-Петербургом. Среди положительных моментов все участники отмечали сохранение возможности посещать Петербург, нераспространение практики выписывать штрафы или делать это для привлечения внимания. Наибольшей критике была подвергнута работа скорой помощи, которая не справлялась с нагрузкой, и отсутствие масок и перчаток, которые купить было невозможно: $B$ maких условиях должны были раздавать маски и перчатки бесплатно через 
органы соизащиты и поликлиники. Но ничего сделано не было (м., 74 года, Лен. обл.); Сразу было понятно, что у нас нет таких возможностей, как в Москве. Там Собянин молодеи! Но у него есть деньги. А у нас их нет, поэтому ничего требовать от Дрозденко нельзя (м., 44 года, Лен. обл.). В целом можно говорить, что образ губернатора несильно изменился на фоне кризисной ситуации.

В Санкт-Петербурге оценки оказались более критическими. С одной стороны, отношение к губернатору и до пандемии было в большей степени негативным. Коронавирус, страшные цифры по количеству умерших, локдаун негативно повлияли на мнение петербуржцев о А.Д. Беглове. Не было ожиданий, что он попытается сделать что-то аналогичное действиям Собянина в Москве: Он преданный ставленник Москвы. Как послушная марионетка, делает только то, что приказано. Сам ни на что не способен (м., 47 лет, Санкт-Петербург); Он не хочет и не может ничего сделать самостоятельно. Боится ответственности, он не должен быть губернатором такого города, как Санкт-Петербург (ж., 37 лет, Санкт-Петербург).

С другой стороны, многие участники фокус-групп отмечали, что сама ситуация предоставила шанс заявить о себе как о лидере, попытаться изменить мнение о себе среди горожан, но губернатор им не воспользовался. Это, с их точки зрения, снижает и так невысокий уровень легитимности А.Д. Беглова: Если бы он захотел, смог бы предложить комплекс мер для Петербурга. Но ему это не нужно, и так хорошо (ж., 27 лет, Санкт-Петербург); Зачем что-то делать? Вот придет приказ из Москвы, тогда, может быть, мы подумаем, что делать. Беглова и Собянина и сравнивать нельзя. Пусть тот делал плохо, с ошибками, перегибами, но он хоть пытался. А наш... даже не знаю, что он и делал (ж., 55 лет, Санкт-Петербург).

Если говорить об оценках муниципальной власти, то больше положительных высказываний прозвучало от жителей сельской местности в Вологодской и Ленинградской областях. Некоторые отмечали, что узнали о своих депутатах только в последний год. Но все эти высказывания носили персональный, фрагментарный характер, что позволяет говорить, что муниципалитеты не принимали единых консолидированных решений. Для участников фокус-групп из Петербурга муниципальная власть никак себя не проявила в этот период и ничем не запомнилась.

Среди основных недостатков во всех регионах люди пожилого возраста называли неспособность организовать помощь и контроль за 
ситуацией через органы соцзащиты, с помощью районных и муниципальных органов власти: Неужели нельзя было договориться и организовать систематический обзвон по телефону или обход по квартирам пенсионеров. Ведь нас закрыли дома, а если мне нужны продукты или лекарства? У меня нет интернета, как жить? (ж., 72 года, Лен. обл.); У нас в селе один-единственный магазин. Начались перебои с некоторьми товарами. На уровне района этот вопрос никак не решался (ж., 67 лет, Вологодская обл.); Наша муниципальный депутат сама за свои деньги договаривалась о доставке продуктовых наборов домой для самых старых и инвалидов. Разве можно так бросать людей и закрывать их под домашний арест! (м., 74 года, Ленинградская обл.); Мы не знали, куда можно позвонить, к кому обратиться за помощью. На звонки в районную администрацию никто не отвечал. Нам приказали сидеть дома, но ничего не сделали, ничего не объяснили (ж., 62 года, Санкт-Петербург).

В условиях режима изоляции, падения уровня доходов, тотального недоверия к федеральным источникам информации о ситуации с пандемией, люди (кроме молодежи) ощутили свою «заброшенность, ненужность».

\section{ВЫвОды}

Подводя итог, можно сделать несколько выводов. Пандемия как вызов, как кризисная ситуация продемонстрировала неспособность элитных групп к принятию консолидированных комплексных мер для защиты населения и минимизации ущерба от пандемии. Органы социальной защиты и здравоохранения не обладают необходимым запасом ресурсов людей, аппаратуры, медикаментов, помещений для борьбы с эпидемией. Политические лидеры федеральной власти или регионального уровня не показали, что могут оперативно решать системные проблемы. Необходимо подчеркнуть, что соответствие системе взаимных ожиданий между управляемым и управляющими - одна из важных составляющих легитимности власти.

В условиях, когда президент является почти единственным источником легитимности политической системы в стране, падение его персонального рейтинга и размывание его образа как сильного лидера повышает риски стабильности режима.

Институционально региональные элиты не восприняли важность создания каналов и площадок для диалога с населением, что снизило 
легитимность принимаемых решений и повлекло за собой нежелание соблюдать меры личной безопасности. Проблема взаимодействия гражданского общества, рядовых граждан и представителей власти только обострилась и артикулировалась в информационном пространстве интернета. Несмотря на подконтрольность СМИ, со стороны власти не последовало сигналов о готовности начать диалог, даже если для решения проблем или снижения их остроты у гражданских организаций есть потенциал. Наиболее ярко это проявилось в отсутствии координации действий между волонтерскими организациями и органами социальной защиты, муниципальной властью.

На фоне распространения коронавирусной инфекции и неблагоприятных внутренних условий готовилось политическое предложение со стороны старых и новых партий, которые начали подготовку к федеральным выборам. Проблемы с легитимностью повлияли на электоральные настроения населения, отразились в невысокой явке на выборах и в партийных предпочтениях во время голосования за кандидатов в депутаты в Государственную Думу.

\section{Литература}

Великая Н. М., Белова Н. И. Социально-экономические риски периода пандемии и практики их преодоления: политика государств и стратегии граждан // Logos et Praxis. 2021. T. 20, № 1. C. 78-88.

Левашов В.К., Великая Н.М. Публичная легитимность российского государства в условиях пандемии и выборов в Государственную Думу // Социальное пространство. 2021. Т. 7, № 4. С. 1-14.

\section{ASSESSMENT OF SOCIAL WELL-BEING AND ACTIVITIES OF POLITICAL LEADERS IN THE COVID-19 PANDEMIC (RESULTS OF FOCUS GROUPS)}

\section{A.V. Shentyakova}

anna_pedagog@mail.ru St. Petersburg State University

St.-Petersburg, Russia

Citation: Shentyakova A. Otsenka sotsial'nogo samochuvstviya i deyatel'nosti politicheskikh liderov $\mathrm{v}$ usloviyakh pandemii COVID-19 (v zerkale fokus grupp) 
[Assessment of social well-being and activities of political leaders in the context of the COVID-19 pandemic (in the mirror of focus groups)]. Vlast' $i$ elity [Power and Elites], 2021, 8 (2): 55-71. (In Russian)

DOI: https://doi.org/10.31119/pe.2021.8.2.3

Abstract. The article examines the results of an applied research on the peculiarities of the perception of the political leaders' activities by residents of 3 regions in the context of the coronavirus pandemic. The aim of the study was to identify the dynamics in the attitude to the political leader on the part of different social groups representatives in crisis conditions. The study of citizens perception of risks, problems, their well-being and the influence of these factors on attitudes towards authorities and political leaders used the focus group method. Group discussions identified a number of changes in the consciousness and assessments of the region's residents. In crisis conditions, the demand for two components of the effective authorities' work has grown significantly. On the one hand, for responsiveness, on the other hand, for feedback and information support of decisions. Both assessment parameters are related to the level of legitimacy of the authorities. The type of settlement and the age of the participants became important factors in assessing the situation of the pandemic and solving the entire spectrum of problems on the part of the authorities. The gender factor showed weak influence.

Among the young participants in focus groups, opposition attitudes towards government institutions and individual leaders intensified. People of the middle age (35-50 years old) noted an increase in negative assessments of the government work, the absence of real leadership qualities among regional politicians. Analysis of the data showed a decrease in the level of trust in the President and a change in the perception of his image among the oldest age group.

Keywords: COVID-19 pandemic, social well-being, political leaders, legitimacy, focus group.

\section{References}

Velikaya N. M., Belova N. I. Social'no-e 'konomicheskie riski perioda pandemii i praktiki ix preodoleniya: politika gosudarstv i strategii grazhdan [Socio-economic risks of the period of a pandemic and the practice of overcoming them: policy of states and strategies of citizens]. Logos et Praxis, 2021, 20 (1). pp. 78-88.

Levashov V.K., Velikaya N.M. Publichnaya legitimnost' rossijskogo gosudarstva v usloviyax pandemii i vy`borov v Gosudarstvennuyu Dumu [Public legitimacy of the Russian state in the context of a pandemic and elections to the State Duma]. Social noe prostranstvo [Social space], 2021, 7 (4), pp. 1-14. 